\begin{tabular}{|c|c|}
\hline \multirow{3}{*}{ 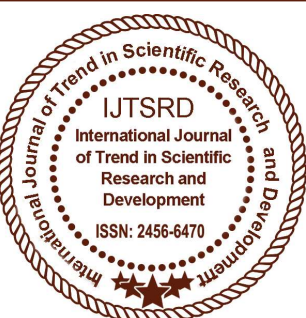 } & $\begin{array}{l}\text { International Journal of Trend in Scientific } \\
\text { Research and Development (IJTSRD) }\end{array}$ \\
\hline & International Open Access Journal \\
\hline & ISSN No: 2456 - 6470 | www.ijtsrd.com | Volume - 2 | Issue -3 \\
\hline
\end{tabular}

\title{
Environmental and Ecological Conflicts of India: A Review
}

\author{
Mohon Rongphar \\ M. Phil Scholar, Department of Political Science, \\ Assam University Diphu Campus, Diphu, Assam, India
}

\begin{abstract}
The term Ecological Distribution Conflicts (EDCs) was coined by Martinez Alier and Martin O' Connor in 1996 to describe social conflicts born from the unfair access to natural resources and the unjust burdens of pollution. Environmental benefits and costs are distributed in a way that causes conflicts. Conflict on nature which harms the biological environment has increased in frequency and intensity of India. This manifest themselves as political, social, economic, ethnic, religious or territorial conflicts or conflicts over resources or natural interests or any other type of conflict. They are traditional conflicts induced by an environmental degradation. The paper focus on how environmental conflict challenges on the contemporary environmental issue. This paper aim to rethink ecosystem conservation perspective and can draw special attention to have our capacity building on ecological system sustainable.
\end{abstract}

Keywords: Review study, conflict by man-man or animal on environment, measure of the conflict

\section{INTRODUCTION:}

Conflict occurs with strong opinion by the public, common people and academicians with the authority, officials, and law and order institutions. Conflict happened due to the affect of the ecological environment and the hill dwellers that had inhabited since from time immemorial. Construction of the dams in various parts of the country has been undertaken by the authority and the Supreme Court play a critical situation to save the life of living organism including the man and animals world. Due to strong demand made by the people elsewhere but the common people need to have a good development and infrastructure communication. The government is

planning to have good improvement on proper infrastructure communication which trying to reach every corner and nook of the country. The study here considered on development project on dams and other related construction activities and how this affects the environment and the living or natural world. Dams have a great deal of positive and negative effects on biological component, man and environment besides controlling stream regimes, consequently preventing floods, obtaining domestic and irrigation water from the stored water and generating power (M. Tahmiscioglu et al., p-761). The concern for the protections of environment was raised since long by writers, scholars, academicians and activists that it has involves the question of the survival of human race on the earth. For the protection of environment, many movements, agitations by environmental activists are being led in different parts of the globe. And as we know that nature is the store house of our resources, thus, we also need to examine deeply the cause and consequences of environmental damage more clearly. The most important problems of environments are due to over 'dependence of resource consumption including the forest, water and fuels and fodders' etc. are widely used. Examining the context of North East India which is rich in natural resource including many rivers and more flood prone region, therefore the main aim of government is to plan more dam's construction for more and benefiting water resources utilisation. Government has examined to construct more dam with more expense and more and more displaced for the native. In Nayak book "Dams and Development in India" aptly analyse that dams have been built for the purposes of flood management, irrigation, hydropower production, navigation and to facilitate recreation which contributes greatly to the growth of a 
nation. In spite of its developmental benefits to nations, it has provoked many debates and criticisms across the world since the emergence of development projects bring significant to social and human impacts in terms of displacement, lost of livelihoods and the rising question of equity and justice. It is well-known the fact that the fundamental promised of large dams in the twentieth century was to provide abundant water supply, irrigation and energy potential. Indeed dams have contributed many benefits even if these have been distributed unevenly to the nation (Nayak, 2016: 1). Dam development is sometime call penetrative development when the certain criteria and pre-requisite developmental facilities are fulfill and meted. World Commission on Dams published entitled "Dams and Development: a new framework for decision-making", in November 2000, discusses a significant debate on dams that it is not only on the benefits and costs of large dams, but more generally to the current rethinking of development programs and decision-making and policy making in a world which has deeply affected by rapid global change. Dams have benefits by changes in water use priorities, physical and land use changes in the river basin, technological developments and changes in public policy expressed in the environment safety, climate control, economic and technical regulations. The practices of operational management on environment must utilise our forest and water resources which must able to adapt themselves continuously the changing circumstances of environment hazards and environment pollution.

Moreover, for the protection of our nature (environment), movement has emerged since long. With this emergence of nature protection or to 'save the earth' some movement has evolved or developed and march the process which come into significant in our daily life. Some of the environmental movements of India include 'Appiko' Movement, 'Chipko' Movement which was led by Sunderlal Bahuguna in 1973 in the Garhwal Himalayas against deforestation, the 'Narmada Bachao' Movement started in 1985 led by Medha Patkar against anti-dam and the 'Silent Valley' began in 1973 and so on. The movements intend to protect and sustain the natural resources which deteriorate because of cutting trees, construction of big dams, and release of waste material by industries, big factories etc. The Environmental Movements in India is mainly involved by women, the poor, and disadvantages masses and thus treating the marginalised people subordinate by developers or by industries. The displaced people have been directly affected their livelihood, income, occupation, etc. due to dam and industries development in the country. This environmental movements in India are not necessarily for the green or 'clean' Earth or for saving mankind but for the very survival of the local poor (Vulli, 2016: 303 \& 304). Environmental conflict or ecological conflict happened due to natural resources destruction. Natural destruction impacted with the forcing of technology and industrial application. When development projects are introduced or are going to construct in the proposed area all the living organisms including the indigenous communities, native plants and animals would be destroyed. When decaying in preservation some disturb living organisms would be extinct such places and sites the native organism will turn down and fall into alien species. In this paper the study will focus while reviewing the related review from this point of view the study make grant to have an ecological satisfaction sustainable into a preservation development? The paper focus on how to measure the ecological conflict between human and animals, sometime man-man conflicts, and disturbing animal world.

\section{II. alleview Study and Rethinking Ecological Conflict:}

The review study has been attempted on Environmental and Ecological conflicts or movement in India will be discussed what various authors and writers had done in their writings those authors or writers includes Carson (1962) finds that use of various polluting elements in the industries affects the life process and other harmful substances that create serious problems especially for the living species. The study also discusses that all unchecked growth of industry has been threatened human health and life of animals are endangered the natural environment. Karan, P. P. (1994) examines the main aspect of the environmental movements in their integrative social and economic effects. The study also focuses mainly on anti-dam and protection of forests resources in several regions where movements are active. Environmental movements in India are an emerging issue because for development through construction of huge dams, other allied infrastructures have been determined. It also finds that Women have been the prominent leaders which they had participated for protection of environment against the cutting of trees in the rainforest areas of the Himalayan gathered by 
contractors or outsider. V. S. Ganesamurthy (2011) contributes that environmental pollution is one of the major problems faced by the world community. It tries to explore the biological environment, the victims of economic exploitation. India is rich in biological diversity including flora and fauna and variety of ecosystems including aquatic species. Governments have determined and proposed to constructs more dams in the country, for the agriculture benefit but this has not meted to the poor farmers to solve the problem of flood and agrarian economy while authority had sometime denied public protest. Therefore, environmental degradation in India has been caused by a variety of social, economic, institutional and technological factors. It tries to explore the primary concerns of Ministry of Environment and Forest gave more emphasis on implementing the acts and policies relating to conservation of natural resources of the country and urged to serve the nodal agency like Environment Protection Act, 1986, etc. regarding degradation of land, water, and air and noise pollution etc. need to minimise such exploitation in the future. It also tries to explore the climate issues advice by UNFCC (United Nations Framework Convention on Climate change) of 1992 and its Kyoto Protocol1997 has been committed to address the global problem on the basis of various principles. Dr. Rao, Uma J, (2013) acknowledge from their writing that India tries to achieve and move on large-scale industries, huge dam construction and more infrastructure development. It urges the development projects not only displaced the local people but it also pollute the rich ecological diversity and rainforest region which destruct and exploits the natural resources from the environmental benign region. It also urges the government which should take initiative plans, rehabilitation policy for the displaced people which is term as 'Project Affected People or PAPs'. It finds that large-scale displacement by big dam's construction and submerges which has occurred worldwide and the $20^{\text {th }}$ century is considered as the 'century of displacement'. Most dams built in India are not satisfactory and existed in the indigenous land and meanwhile, the indigenous people's culture is being affected. Bhattecharjee (2013) finds that Assam on one hand and northeast describe as describe as biodiversity hotspot region as a whole, the NGOs of Assam play an active role for environmental conservation and preservation and making the nature safety and sustainable in the global levels. The northeast NGOs has also emerged to appeal to sustain the environments which are basically in the ecological system and seismically active prone region. It urges that these region need to sensitise giving an awareness campaign to train the local people in order to ensure and to restore the environment including the early living organisms by messaging the Environmental Justice Movement in the long run. It also finds that due to ecosystem destruction the continuous illegal hunters of wildlife and migratory species including birds, animals, etc. have to stop and must initiate for species conservation seriously in the near future. Bahar Dutt (2014) observes that the North and the Northeast India is defined as richest biodiversity or 'hotspot' region with abundance of natural or water resources. The author tries to explore the Northeast that ranges from tropical evergreen to alpine and are home to 5,000 plants, eighty-five mammal species and 500 birds exist in it. It urges that northeast biodiversity must conserve before it is lost to the dam. Due to dam construction the natural course of the Dibang River by diverting the water which ignores the importance of the river which faces the problem of tradition, culture and the religious sentiment of local people. It urges that like Subansiri project, Dibang project site has existed in the earthquake prone zone. Large dams in India has block and altered the natural flow regimes of the river which drives the ecological processes in the downstream areas of Assam. The author argues and deliver that fragile and magical connection between the upstream and downstream waters is disrupted by large dams with a disastrous effect on the economy of the people. Some downstream impact concerns include: loss of fisheries; changes in wetland (beel) ecology in the floodplains; impacts on agriculture and the ecology of riverine islands and tracts. It also discusses ecosensitive sites which will be severely damaged from the discharge of hot water from the power plants into the big rivers. Guha Ramachandra (2014) observes that as Chipko movement is the first environmental or ecological conflict or movement of Himalayan people against clear-cutting of forests by timber contractors. Environmental movement in the west, stemmed to desire to protect endangered animal species and natural habitats. In India, it arose out of the imperative of human survival. This was an environmentalism of the poor that sought to promote social justice with sustainability. It urges that three environmental challenges posed by the economic rise of India and China viz. threat of rapid and irreversible climate change, both have environmental and social impacts beyond their borders and both posed to environments 
themselves. In 1970s pollution control and natural protection has been enacted and in the 1980s and 1990s, the finest of environmental movement sought to marry Science with Sustainability. Today, environmental in India a basket-case marked by polluted skies, dead rivers, falling water-tables, everincreasing amounts of untreated wastes, and disappearing forests. Nayak Arun Kr. (2016) discusses that dams are considered as an agency of development and it is contributed to flood management, hydropower production, irrigation, navigation and supplying water for urban and industrial needs. The author urges that dam development affects the tribal people while compensation for them is ineffective since the beginning of dam development in the country. It urges that the Hirakud Dam were fulfilled even after fifty years were massive social misery by submerging hundreds villages and displacing about thousands people on one hand and conflicts with the government, farmers, local people and stakeholders on the other. While the ecological region get disturbed due to clearing the forest region.

Thus the above said review of literature states that ecological conflict or environmental movement raised due to human activity, natural resources consumption, consuming forest products, etc. has been included under this study. This study of literature review that reflects the destruction and degradation of natural resources on the Mother earth which affect the life activities in day to day pronouncement. The study aims to rethink how natural environment should management efficiently and meaningfully into the circle of development under the control of sustainable balance system. Today, our natural resource likely that extracted or consumes forest product which are very limited and critical for our future sustenance. In this review of the study we should think more penetrative and inductive methods to conserve more rather than consumption because if we consume more and more without any restriction our natural resources would be degraded and which might be extinct. Till today, our human society did not think much about the conservation and preservation of natural resources. But sometimes people also may think that why we should conserve our natural resources mainly by the common people, they did not know what would be happened in the future crisis. Most common people think that when crisis happened skipping outside protective awareness knowledge. Either general people they listen the comments of leaders or listening or following the rules and laws of the rights of environment by the animals and human in separation. This major causes challenges ecological conflicts in the Eco-sensitive region of the country or state as well as at the local level. The eco-sensitive sites and ecological functioning region has been decreasing and narrowing at a rapid rate that had challenged in this modern world of environmental politics.

\section{Some Major Challenges of the Review Study:}

There are some major challenges which have been reviewed in the above study. They are as below -

1. In this review, the knowledge sticks that the exploring the biological environment from the unexplored region say for example, the deep forest region of Lumbajong region attached to Lumding region, Kaziranga forest region attached to Bisarpo to Lanklokso of Samilangso region and some other places or site has categories as animal corridor, elephant corridor etc. Here it can be clearly states that all the above mentioned region or site has been inhabited by the tribal people of the concern district called Karbi Anglong district of Assam. This region has been under the perview of Eco-sensitive region the tribal people live together with or along with the animals in the deep forest or for cultivation purposes.

2. In this review of the related study expresses that exploration and protection of natural and biological life on the earth is one of the major challenges in our contemporary period for any discipline of the study.

3. Apart from exploration and protection measures, conservation and preservation of the concern natural resources is another major challenge in this study.

4. Besides, preservation of ecosystem region sustainability of natural resources data base technique is another challenge for sustaining the major environment.

5. The concern review states that how pollution can be minimised and how the surrounding people can bare the serious air polluting every day. Every day the polluters may not check how much this has polluted in the fresh air. Skipping the polluting air in the air rethink how many people have been breathed out per second the polluted air in the surrounding industrial areas. These polluting air, water, noise etc. which has been endangering the 
natural environment and the biological components.

6. This review of study expresses and opines that protection of forest resources or protection of ecosystem region occurs where ecological movements are active. Ecological conflict or environmental movement had emerged due to the impact of development projects or construction in the ecosystem region. "Protection of ecosystem region, save nature save life" considered as one of the most important challenges in this literature review.

7. In this study, academicians, scientists, authority etc. should have to think and to re-think the concern affecting natural environment in recent time why badly. This review depict and suggest that rapid growth of dam construction and other allied development should have to pay the debt as polluter pays principle has been attributed.

8. It is to say that there is one of a big gap between conservation of biological diversity and the development perspectives on projects like dams and other allied construction. To fill the gap between save life and smooth living and communication facilities this two components should keep in mind how to tackle the worse form of polluting earth and human society pay their smooth living. These reflect to one to other life process. Because one wins other lose for the development as well as for the conservation perspective.

9. The Government of India should take initiative more not only the environmental laws, acts and policies but which is also needed to consider the human activity which hampers the indigenous people due to development projects that had been destructed live and property due to evacuation.

10. Relating study of the environmental or ecological conflicts should manage the ecosystem functioning provide a framework for planning biodiversity conversation. These are coarse and fine filter approach refers to conserving representative samples of all the ecological communities in a region can facilitate conservation of the majority of species. Species, ecosystems and features that "fall through" the Coarse - filter for example species that depend on a specific habitat feature need to be conserved by a Fine - filter approach such as protecting wildlife trees.

11. Adaptive management decisions can be improved over time by learning from experience. This review rethink aim to improve environment more adaptation. Therefore environment management would be improving scientifically. Our ecosystem base maintains the key characteristics of ecosystems that sustains species and ecological processes but also supports some human intervention for economic or social purposes.

12. Land and water dedicated to the protection and maintenance of biological diversity and associated cultural resources have to take special initiative including the Project Affected People (PAPs) and Project Affected families (PAFs) for them have not yet taken into much effective consideration on the circle of protection.

13. Rethinking and focusing on environmental rehabilitation have been influenced by the Gandhian tradition of constructive work, others by religious reform movements, and yet others by the instance of international relief organisations. All these activities are the programs of ecological restoration. See for example, Chipko movement also called ecological movement is one of the best examples of ecological conflict during the pre and post independence period of India.

\section{Ie Ecological Conflict Measures:}

Ecological Conflict are characterised by the principal importance of degradation in one or more of the following fields- firstly, over-use of natural resources, second, overstrain of the environment's sink capacity (pollution), and thirdly, impoverishment of the space of living (Stephan Libiszewski, 1992: 14). To measure this ecological conflict we have to be more serious while reading on environment and ecology. In simple there were some points that try to suggest upto the author expectation. They are -

\section{i. Understand and Defining of Conflict:}

The foremost part of ecological or environmental conflict measures in simple such as the first step of Environmental conflict were 'to understand and defining of the conflict'. One stakeholder might that the conflict is about access to resource another might think it about land tenure and still another might think it about constitutional rights to a certain set of bahaviours. Stakeholder identification is the next step that permanently involves in analysing each individual stakeholder's needs, interest and position. The NGO is the primary stakeholder that number of communities surrounds the conservation concession, composed of different indigenous groups. The fourth, 
set of stakeholders is the regional governments. The fifth, stakeholder is the national government's agency that oversees protected areas like national parks, conservation concessions and forest reserves.

\section{ii. $\quad$ Regulating Ecological Areas:}

The ecological area is hugely important as forest for regulating the flow of water through the region there are stakeholders all through the continent and then to the states level. Such forests are hugely important for regulating climate and producing oxygen so in the end everybody is a stakeholder. The entire planet becomes a stakeholder. However, environmental conflicts are socially complex because environments produce a series of ecosystem services that exist at the very local level all the way to the global scale. National park is a protected area in the state level of which incredibly important for the temperate or tropical rain forest it holds. On every mountain there is huge threat from agricultural expansion and resulting deforestation up into the high elevation slopes. The problem is that there are communities established on the mountain who have been living there from time immemorial with a certain set of agricultural, hunting and forestry practices that they have traditionally used for subsistence livelihoods. Once the mountain became part of the park those actions were no longer legal. So the park managers were faced with these questions of what do we do with the populations that are living there? How do we administer the mountain in such a way that they can continue to make their livelihoods? And how do we try and curb the deforestation that going on? Therefore, to suggest in few lines we did a social survey, a household survey, soil sampling and an agricultural assessment and understand what is going on throughout this mountain. One of the strategies the park had been considering was moving entire villages off the mountain which would be highly controversial. But should come in with a set of recommendations for agro-forestry interventions hat would improve the agricultural yield for these communities while reducing their impact on and their need to expand to the higher elevation slopes. Another set of recommendation was two-fold that one was to do agriculture and agro-forestry development projects with the local communities to minimise their need to expand. Second, was improving the forest patrolling done by the park to stop these external actors from coming in and conducting illegal activities. In various states of the world, conservation concession management plans have focused very explicitly on ecology and biology without a lot of emphasis on the social dynamics. Therefore, it is time to write a new management plan that was an excellent opportunity to really inform the new management plan with the social dynamics. Another intellectual thinking come in this writing that there are a lot of people who engage in small-scale mining illegally that produces a lot of conflict with the formal mining sector and with indigenous groups whose land gets invaded as well as with land managers who are contracted by the state to manage these forests for conservation sake. The paper is trying to do is to see if we can create a model for conservation that can incentivise people not to engage in these destructive practices and not to mine in protected areas. Here, the trick is designing land use strategies that accommodate everything to create a mosaic of land uses that are complementary rather than competitive.

\section{iii. Agriculture Plans: \\ and Management \\ Action}

To consider Forest management actions, agriculture development projects will complement the management plan that can reduce the need to hunt in the concession and improve people's ability to make their livelihood outside the concession. One the basis of working on identifying communities to do aquaculture projects, because fish farming is a potentially important source of revenue. However, with a changing climate increased rates of change all around in environmental aspects. So naturally people's needs and interests and positions around those environmental aspects change and give rise to conflicts. Whether climate change will create conflict, rather how do we manage those conflicts productively and use a changing climate as an opportunity to reinforce positive social relationships rather these conflicts to degrade into violence or into political deadlock or economic conflict. Deliberately, managing conflict needs and interest in a way would be productive and lead to social benefits rather than just reacting and trying to mitigate disaster after disaster after social disaster. Whether this might be positive or negative sense, conflict is just an opportunity for change (Renee Cho:2013). When conflicted change occurred, and changes, means social change development because conflict and issues always appears from social environment. Last not the least conflict solution is that human consumption base on by the company, industry, etc. should minimise its uses of natural resources. Development projects including construction of dams, roads, railways and building industries in the state or 
country kills the living organism of a region is taken into consideration.

\section{iv. Man-Man Conflict:}

"Man-man conflict" occur due to introducing the modern system of development, this is how if Dam construction is considered as a factor of development then this factor impacted the natural environment this means while destructing and excavating the human livelihoods man-man conflict had happened internationally. Since, Man - animals conflict had been occurred prior to the coming of industrial revolution this is nothing but increasing population while earth in a static position. For example, Dam construction in the North east region considered as "Power House State or Power Hub State" then, all the projects where it has existed and exist in the coming years in the North east India will be raising the 'sociopsychological issues' among the Indigenous Communities, conflict between common people and the authority.

\section{v. Disturbing Animals World:}

"Disturbing animal world" refers that conflict also can occurs with the destruction of Eco-deep forest, polluting the eco-green environments, etc. this naturally inhabited species will be disturbed. Therefore, the disturb animals moves from one to another sites where human settlement areas may also attacked by the disturb animals to those people living near the forest areas. In this sense, of view the local people will also attempt to hunt such disturb animals to save between man-animals interference. This is how this paper aim to tell that not to destroy such naturally species and not to destruct the animals hub which has been inhabited since the beginning.

\section{Conclusion:}

In conclusion it can clearly say that the ecological region, biological conservation system, ecosystem region, eco-sensitive region, scared grove, etc. environmental conflicts happened due to introduction of projects. Construction of big and large dam in the concern region is one of the major challenges in the conflict of ecological perspective. Projects construction is nothing but, it is the human activity while the authority always tells that consumption of forest resources by the local people who had been inhabited in the adjoining areas of the states become a victim of all these activities. But this is not the correct opinion given by many delegates or officials from the gone days. This is why development projects construction like big or small dams, building industries, factories, introducing rural to urban like smart cities or town that are rightly affected the live and livelihood of the local or indigenous people. This excavated people's property which had been left out totality, they should migrate in the nearby forest areas. As for example, due to introduction of Guwahati zoo, Guwahati oil refinery, Numaligarh oil refinery, coal mining at Patkai Hills, introducing smart city near the hills sides of Kamrup District, construction of Dams, etc. mainly affects the tribal local people only. This is nothing but creating and neglecting the tribal people, destroying the innocent people by the state government of the country and also where tribal or indigenous peoples get highly depressed from the concern state(s) government. Government has been given the acts and policies or laws for the rights of the tribal people to settle in the forest for species cultivation but had thrown away.

Rethink to our own society having awareness for volunteers groups have taken up appropriate soil conservation measures like the plugging of gullies, construction of small check-dams and the plantation of fast growing grass species. Study is like a network of words and language by citing an example successful teco-restoration work originated in a process of struggle. Reconstruction work can proceed hand in hand with struggle. In the last part of an analysis, the main theme is that some ecologists do not view the purview of solutions to environmental problems as 'real' science. On the other hand, some ecologists do not view the purview of knowledge as valuable for its own sake because this activity may not immediately or directly benefit human existence. There should be no conflict between ecology as a rigorous science and ecology as a basis for solving environmental problems. In another way, a strong science leads to sound management. For management, ecology must identify the likelihood of a system failure and provide society with choices among alternative actions that will minimise this likelihood. Ecology as science and ecology for environmental decision making should be equally fostered and it should be recognised that two endeavours are equally valuable. There is no reason that ecologist cannot perform both functions, but an individual's work should receive a different kind of professional evaluation for each one. Lastly, when ecological conflict occur there is some major critical conflict between human - wildlife conflict are widespread, when resource use by human and non-human animals overlap and contradictory. We propose from this 
literature of the above reviews that investigating broader ecological context of conflict ('ecology of conflict') might help to explain variation in conflict patterns leads to a better mechanistic understanding and improved prediction and management. Researcher usually focuses on the process of proximate including human group's sizes and behaviours, attractant management and bahaviour of humans and wildlife involved. Proximate inquiry conflicts and how to avoid them but renders limited insight into the timing, location and causes of broader conflict patterns. Therefore, improved conflict management addresses underlying ecological stressors such as protecting or restoring natural food (example, from overharvest or inhabitat destruction). A special focus on understanding the underlying ecology of conflicts could focus limited resources on mitigation efforts including education and attractant management when and where ecological conflicts are most likely to occur. This might be possible that applying multiple testing approaches broadly might help to increase such understanding of ultimate drivers of humanwildlife conflict in any system while identifying commonalities among human wildlife conflict systems worldwide (Artelle et el., 2016). Thus, to minimise human activity in the deep ecological region human - animal conflict might be possible to minimise, is one of the simple step of ecological or environmental conflict. Controlling population and natural resources uses should take more initiatives as an effective part of an analysis.

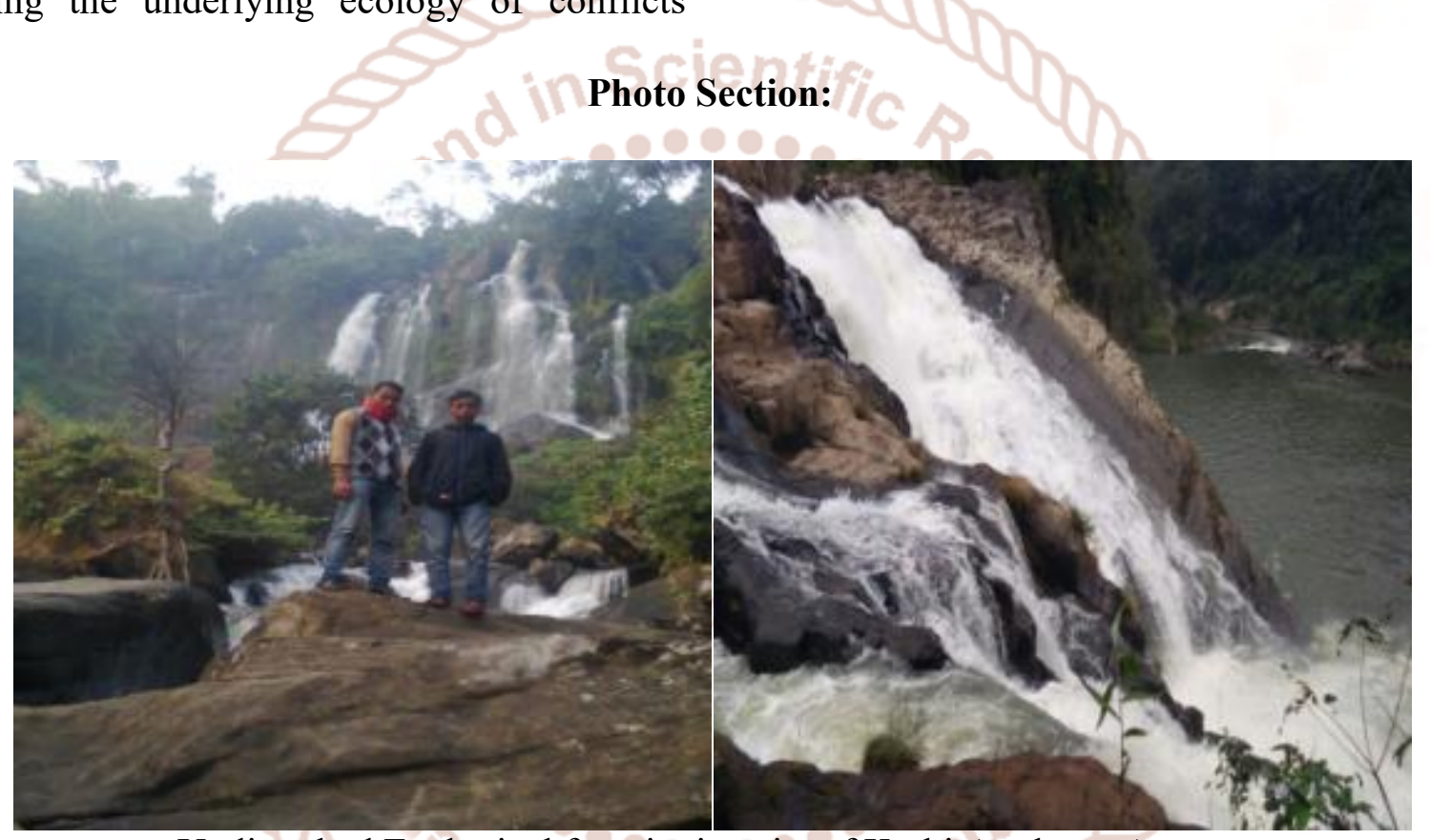

Undisturbed Ecological functioning site of Karbi Anglong, Assam.

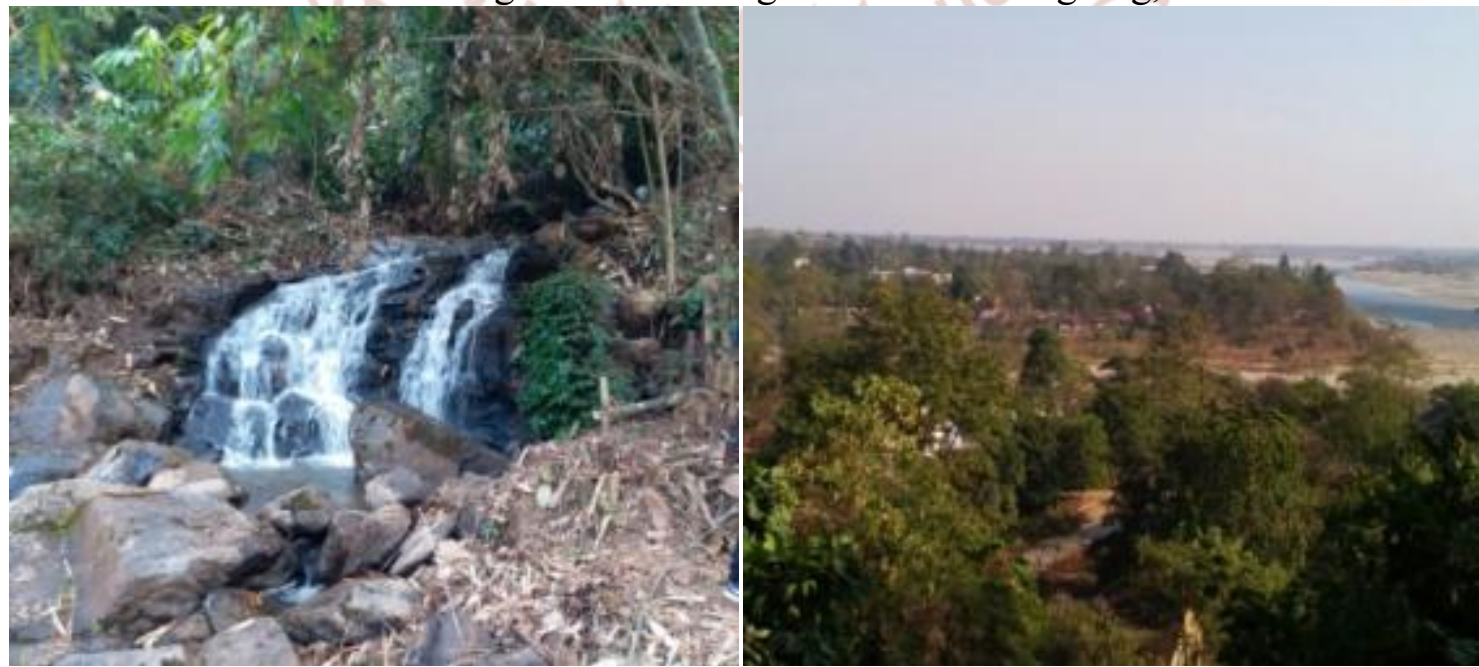

Undisturbed eoclogical site of karbi Anglong and right photo disturbance of ecological areas of Dhemaji Arunchal border. 


\section{Bibliography:}

1) Salome Van Jaarsveld Bronkhorst \& Urmilla Bob (2010) "Environmental Conflicts-Key issues and Management Implications", www.accord.org. Accessed date on $19^{\text {th }}$ March 2018.

2) 'Ecological Concepts, Principles and Application to Conservation', http://www.biodiversitybc.org. Accessed date on $19^{\text {th }}$ March 2018.

3) Sarah Jewitt (2008) "Political Ecology of Jharkhand Conflict", https://onlinelibrary.wiley.com. Accessed on date $19^{\text {th }}$ March 2018.

4) Kyle A. Sean C.Anderson \& Chris Darimont, (2016) "Ecology of Conflict: Marine Food Supply Affects Human-Wildlife Interactions on Land", https://www.ncbi.nlm.nih.gov. Accessed on date $19^{\text {th }}$ March 2018.

5) Singh, S (1991), 'Environmental Geography', published by Prayag Pustak Bhawan, Allahabad, India, pp-21-22.

6) Vulli Dhanaraju (2016) 'A |rextbook tof Environmental History in India', Dominants publications, Daryaganj, N. Delhi, pp- 305, 313, $316,317,318,319,321,322,352,353$.

7) Bahar Dutt (2014) "Green Wars- Dispatches from a Vanishing World", published by Harper Collins, N. Delhi, pp- 45-58.
8) Arora \& Awasthy (1996) Political Theory, published by Har-Anand, New Delhi.

9) Nayak, A.K. (2016) "Dams and Development in India" published by Rawat Publication, Jawahar Nagar, Jaipur (India), pp-54-139.

10) P.D., Sharma (2014-15) "Ecology and Environment", 12th revised edition, S Chand publication p-569.

11) R. Guha (2000) Environmentalism - A Global History, published by Penguin Group, Haryana, India.

12) Madhav Gadgil \& Ramachandra Guha "Ecological Conflicts and the Environmental Movement in India", www.wgbis.ces.iisc.ernet.in, pp-107-108. Accessed date on 16th March, 2016.

13) Stephan Libiszewski (1992) "What is Environmental Conflict?", p-14, www.css.ethz.ch. Accessed date on $22^{\text {nd }}$ March 2018.

14) Renee Cho (2013) "Finding Solutions to Environmental Conflict", http://blogs.ei.columbia.edu. Accessed date on $23^{\text {rd }}$ March 2018. 